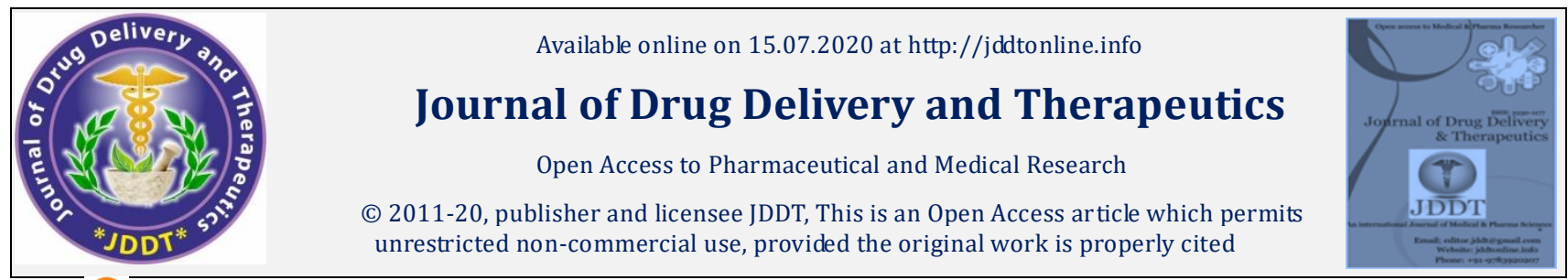

Open Access

\title{
Design and Synthesis of Novel Anticancer Peptide Nanoparticles
}

\author{
Zhi-Gang Sun 1,2*, Zhi-Na Li ${ }^{1}$, Bao-Chan Yang ${ }^{3}$, Liang-Hui Zhao ${ }^{4}$ \\ 1-Linyi Central Hospital, Linyi 276400, Shandong, China \\ 2-School of Life Sciences, Nanjing University, Nanjing 210023, Jiangsu, China \\ 3-College of Chemical and Environmental Engineering, Shandong University of Science and Technology, Qingdao 266590, Shandong, China \\ 4-School of Clinical Medicine, Weifang Medical University, Weifang 261000, Shandong, China
}

\begin{abstract}
Cancer has now become a common disease affecting human health. Existing cancer treatment drugs can no longer meet the growing needs of cancer patients, and the emergence of anticancer drug resistance has exacerbated this phenomenon. By designing and synthesizing new anticancer peptide nanoparticles and studying their anticancer effects, new strategies for cancer treatment may be obtained. Novel anticancer peptides are synthesized by adding basic amino acids and solid-phase synthesis technology, and their structural information is determined by mass spectrometry. Nanoparticles of anticancer peptide were synthesized by nano-self-assembly technology. Two novel anticancer peptides exhibited anticancer activity, one of which was assembled into nanoparticles. The theoretical isoelectric points of the modified SZG3 and SZG5 are all greater than physiological pH, and will be positively charged under physiological conditions. The estimated half-life of SZG3 and SZG5 is significantly extended $(30 \mathrm{~h})$, which is beneficial to increase the efficacy and reduce toxic and side effects. SZG3 and SZG5 have a good inhibitory effect on tumor cells and have low toxicity to normal cells.
\end{abstract}

Keywords: anticancer peptide, study, design, cancer, nanoparticles

Article Info: $\quad$ Received 04 May 2020; $\quad$ Review Completed 21 June 2020; $\quad$ Accepted 02 July 2020; $\quad$ Available online 15 July 2020

Cite this article as:

Sun ZG, Li ZN, Yang BC, Zhao LH, Design and Synthesis of Novel Anticancer Peptide Nanoparticles, Journal of Drug Delivery and Therapeutics. 2020; 10(4):102-107 http://dx.doi.org/10.22270/jddt.v10i4.4156

*Address for Correspondence:

Zhi-Gang Sun, Linyi Central Hospital, Linyi 276400, Shandong, China

\section{INTRODUCTION}

The morbidity and mortality of cancer are increasing rapidly around the world, which is related to the aging population, population growth and the distribution of the main risk factors for cancer, and partly to the social and economic development. Lung cancer is the most common diagnosis of cancer $(11.6 \%$ of the total) and the leading cause of cancer death $(18.4 \%$ of the total cancer deaths), followed by female breast cancer (11.6\%) and prostate cancer $(7.1 \%)$ (1).

Cancer treatment methods mainly include surgical treatment, radiotherapy, chemotherapy and molecular targeted therapy, but in the course of treatment, cancer patients have developed certain resistance to certain drugs. Mechanisms of drug resistance include drug inactivation, drug target changes, drug outflow, DNA damage repair, and cell death inhibition(2). Therefore, the development of new anticancer drugs is needed to solve the problems caused by the increase in cancer incidence and the emergence of drug resistance.
Antimicrobial peptides are a class of peptide active substances produced by animals, plants and microorganisms against external pathogens(3-6). As people continue to study antimicrobial peptides, it is found that some of the cationic antimicrobial peptides have anticancer activity and show a strong killing effect on a variety of tumor cells(7-10). Compared with normal cells, there are more negatively charged molecules on the surface of tumor cells, such as sialic acid(11), etc. The cationic antimicrobial peptides generally have an amphiphilic structure: they are both hydrophilic and lipophilic(12), where lipophilicity binds them to cell membrane lipids, and the hydrophilic nature of cations causes them to interact with water or negatively charged residues. Based on this combination, this amphiphilic structure allows it to bind to the surface of tumor cells with negative charges on the surface, which lays the foundation for its interaction with tumor cell membranes and selectivity. In this study, anticancer peptides were obtained using solid-phase synthesis technology, and their anti-tumor activity was measured, and then the nano self-assembly study was conducted. 


\section{MATERIALS AND METHODS}

\section{Materials}

\section{Cell lines}

Human cervical cancer HeLa and human embryonic kidney 293T cells are all derived from the State Key Laboratory of Pharmaceutical Biotechnology of Nanjing University.

\section{Reagents and equipment}

MTT (Shanghai Aladdin Biochemical Technology Co., Ltd.), DMSO (J\&K Scientific Ltd.), fetal bovine serum (WISENT Inc), multifunctional microplate reader (Tecan M200 PRO), nano-potential particle size analyzer ( Malvern Nano-ZS),
DMEM (Vicent Biotech Co., Ltd.), CO2 cell incubator (Thermo Forma).

\section{Novel anticancer peptides SZG3 and SZG5}

The SZG3 sequence is MAMVGTRHHHHH with a purity of 95.938\%; the SZG5 sequence is MWAIVLLRHHHHH with a purity of $97.298 \%$, all synthesized by Hefei Guo peptide Biotechnology Co., Ltd. through solid-phase synthesis technology.

\section{Method}

Design of novel anticancer peptides

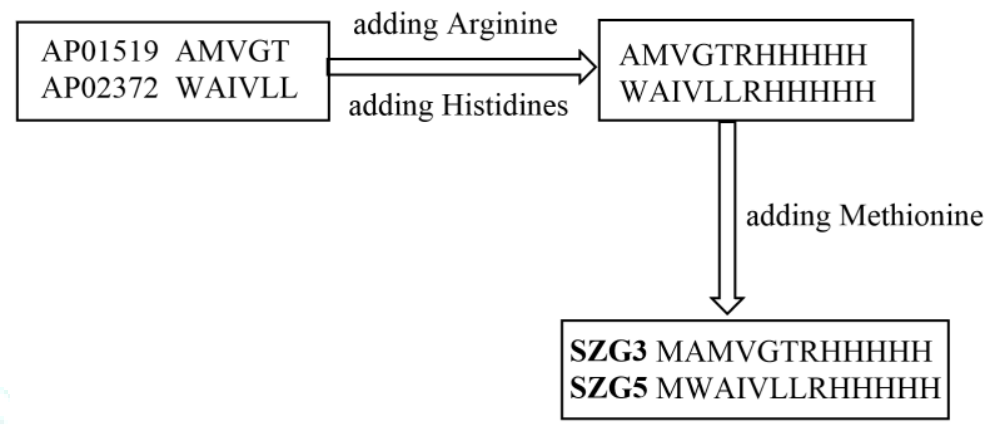

Figure 1 Design strategy of new anticancer peptides

Two anticancer peptides AP01519 and AP02372 with anti-tumor activity were screened in the Antimicrobial Peptide Database (APD); adding the basic amino acid arginine to the $\mathrm{C}$-terminal end of the above two amino acids resulted in stronger tumor specificity Cationic peptide; adding 5 histidines to the $\mathrm{C}$ segment makes the whole peptide chain more cationic; adding methionine to the $\mathrm{N}$-terminus makes it have the potential for bacterial expression. ProtParam was used to analyze the basic parameters of the new anticancer peptides.

\section{MTT experiment and apoptosis experiment}

MTT experiment: Hela cells and 293T cells in logarithmic growth phase were used, and the cell concentration was adjusted to $5 \times 10^{4}$ Cells $/ \mathrm{mL}$ with culture medium containing $10 \%$ fetal bovine serum, and distributed into 96 -well plates. After 12 hours of incubation, different concentrations of peptides were added and a blank control was set. The absorbance at $490 \mathrm{~nm}$ wavelength was measured by MTT method. Apoptosis experiment: Hela cells in logarithmic growth phase were used, and the cell concentration was adjusted to $5 \times 10^{4}$ Cells $/ \mathrm{mL}$ with culture medium containing $10 \%$ fetal bovine serum. After 12 hours of incubation, different concentrations of peptides were added and a blank control was set. Annexin V-FITC/PI double staining apoptosis detection method was used to detect the apoptosis process.

\section{Anticancer peptide nanoparticle self-assembly experiment}

Take $10 \mathrm{mg}$ of the synthesized amphiphilic anticancer peptide and dissolve it in PBS buffer (pH 7.4). At a constant temperature of $37^{\circ} \mathrm{C}$, the anticancer peptide was suspended by ultrasound for $15 \mathrm{~min}$ and $30 \mathrm{~min}$, respectively. The ultrasonically treated amphiphilic anticancer peptides were placed in a constant temperature incubator, incubated at $37^{\circ} \mathrm{C}$ for $35 \mathrm{~min}$, and then taken out to observe the self-assembly of amphiphilic anticancer peptides. The nano-self-assembly was preliminarily observed with a nano-potential particle size analyzer, and the microstructure formed after anticancer peptide self-assembly was observed with a transmission electron microscope(TEM).

\section{TEM imaging experiment}

The sample was negatively stained with $5 \%$ phosphotungstic acid, dried and tested with a transmission electron microscope (JEM-2100), with a voltage of $200 \mathrm{KV}$ and an electron beam current of $102 \mu \mathrm{A}$. 


\section{RESULT AND DISCUSSION}

\section{Mass spectrum of novel anticancer peptides}

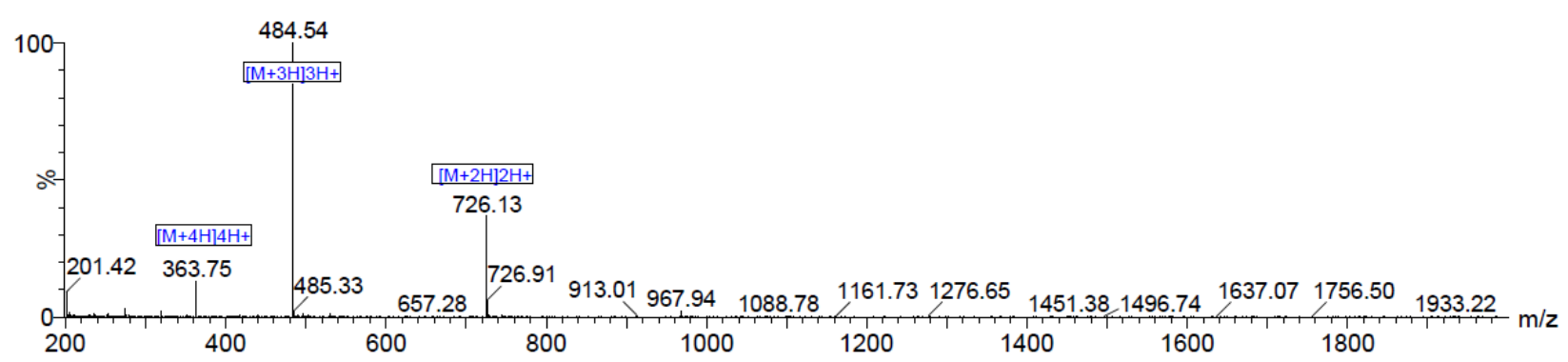

Figure 2 Mass spectrum of SZG3

The mass spectrum of SZG3 is shown in Figure 2, with theoretical value of 1450.67 and observed value of 1450.62.

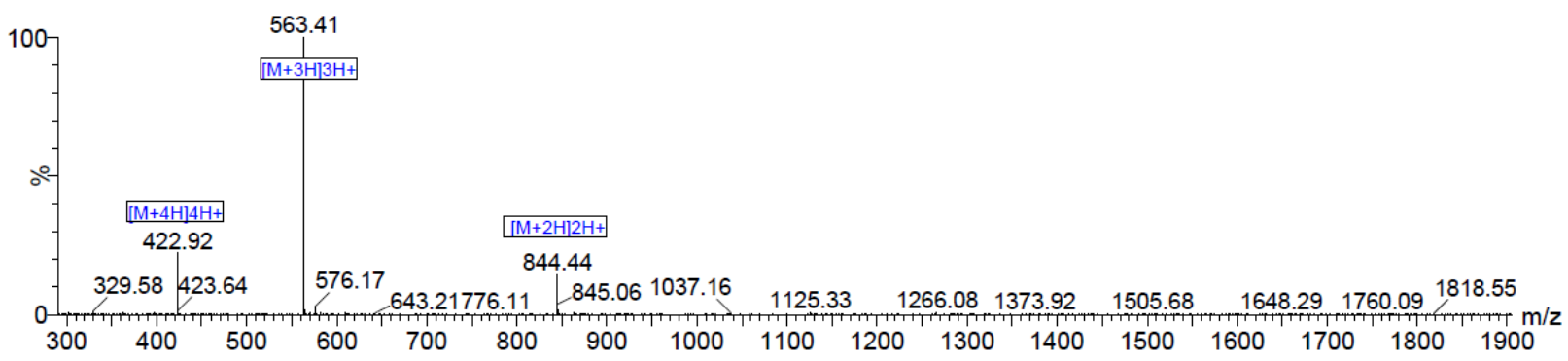

Figure 3 Mass spectrum of SZG5

The mass spectrum of SZG5 is shown in the figure above, the theoretical value is 1850.08 , and the observed value is 1849.98 .

\section{Analysis of the basic properties of new anticancer peptides}

Table.1 Basic properties of new anticancer peptides

\begin{tabular}{|l|c|c|c|c|c|c|}
\hline Name & Sequence & \multicolumn{1}{|c|}{$\begin{array}{l}\text { Theoretical } \\
\text { pI }\end{array}$} & $\begin{array}{l}\text { Grand average } \\
\text { of } \\
\text { hydropathicity } \\
\text { (GRAVY) }\end{array}$ & $\begin{array}{l}\text { Instability } \\
\text { index }\end{array}$ & $\begin{array}{l}\text { Aliphatic } \\
\text { index }\end{array}$ & $\begin{array}{l}\text { Estimated } \\
\text { half-life(h) }\end{array}$ \\
\hline AP01519 & AMVGT & 5.57 & 1.360 & -25.96 & 78.00 & 4.4 \\
\hline SZG3 & MAMVGTRHHHHH & 9.59 & -0.983 & 21.35 & 32.50 & 30 \\
\hline AP02372 & WAIVLL & 5.52 & 2.867 & -30.87 & 260.00 & 2.8 \\
\hline SZG5 & MWAIVLLRHHHHH & 9.59 & -0.108 & 20.77 & 120 & 30 \\
\hline
\end{tabular}

The theoretical isoelectric point (pI) of AP01519 and AP02372 are less than the physiological pH, and will be negatively charged under the physiological conditions; the theoretical isoelectric points of SZG3 and SZG5 after modification are both greater than the physiological $\mathrm{pH}$, and will be positively charged under the physiological conditions. The GRAVY of AP01519 and AP02372 were higher than 1, indicating that they did not have good hydrophilicity; the GRAVY of SZG3 and SZG5 after modification were lower than 1 , indicating that the two anticancer peptides had good hydrophilicity. All of the four anticancer peptides have a certain degree of liposolubility, and the modified SZG3 and SZG5 have decreased liposolubility and increased amphiphilicity. The instability indexes are all less than 30 , so they can be considered stable. The estimated half lives of AP01519 and AP02372 were less than $5 \mathrm{~h}$, indicating that repeated administration was needed to reach the steady-state concentration, and it would increase the toxicity and side effects to the body; while the estimated half lives of SZG3 and SZG5 were significantly prolonged (30h), which was beneficial to increase the efficacy and reduce the toxicity and side effects. 


\section{Tumor cell inhibition and cytotoxicity experiment}

Table.2 Tumor suppressive activity and cytotoxicity of novel anticancer peptides

\begin{tabular}{|l|l|l|}
\hline & $\mathrm{IC}_{50}(\mu \mathrm{M})$-Hela & $\mathrm{IC}_{50}(\mu \mathrm{M})-293 \mathrm{~T}$ \\
\hline SZG3 & 68.54 & $>100$ \\
\hline SZG5 & 68.73 & $>100$ \\
\hline
\end{tabular}

As shown in Table 2, the IC 50 values of SZG3 and SZG5 to HeLa cells are $68.54 \mu \mathrm{M}$ and $68.73 \mu \mathrm{M}$ respectively, while the toxicity to $293 \mathrm{~T}$ cells is relatively low. This indicates that SZG3 and SZG5 have good inhibitory effects on tumor cells.

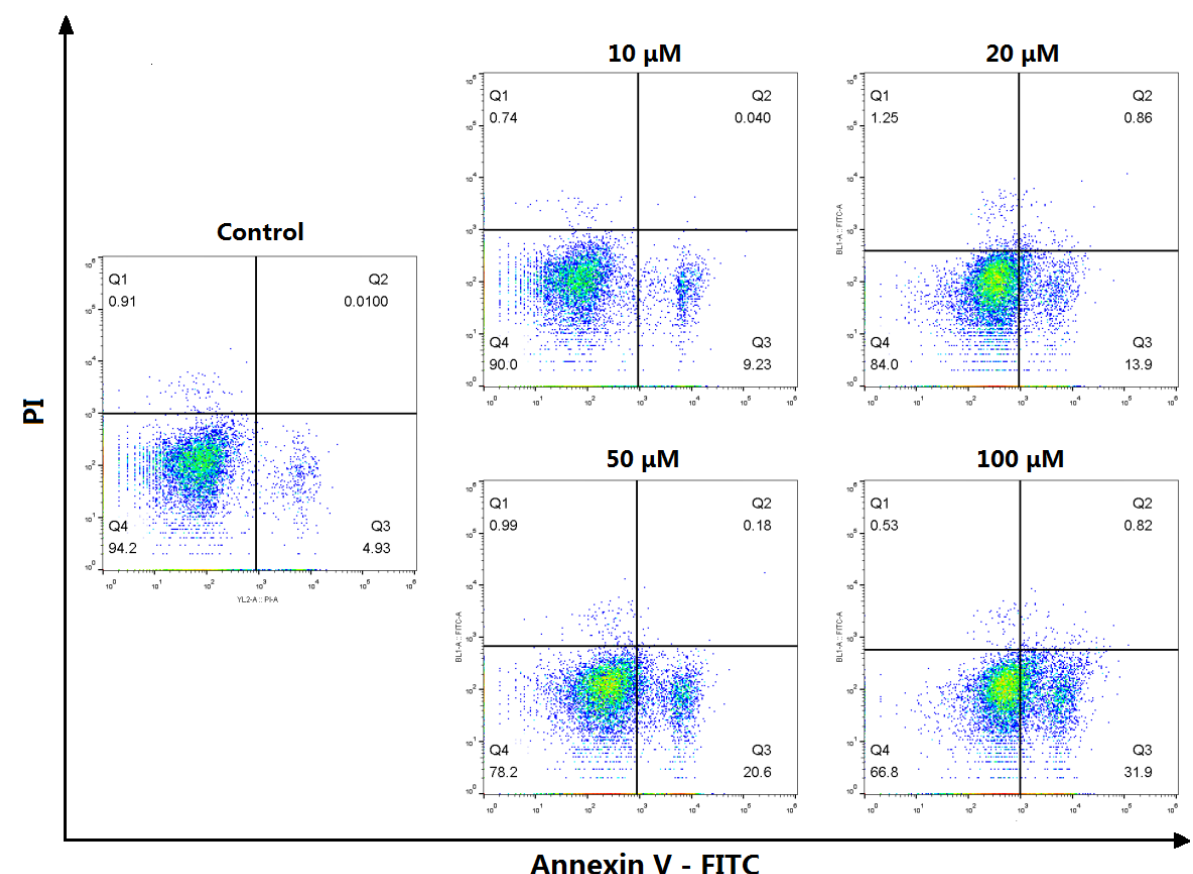

Annexin V - FITC

Figure 4 Apoptosis effect of SZG3 on Hela cells

It can be seen from Fig. 4 that after incubation for 24 h, SZG3 has apoptosis inducing effect on HeLa cells at a lower concentration, but higher concentration is required to achieve obvious apoptosis effect.

\section{Nano self-assembly of SZG3}

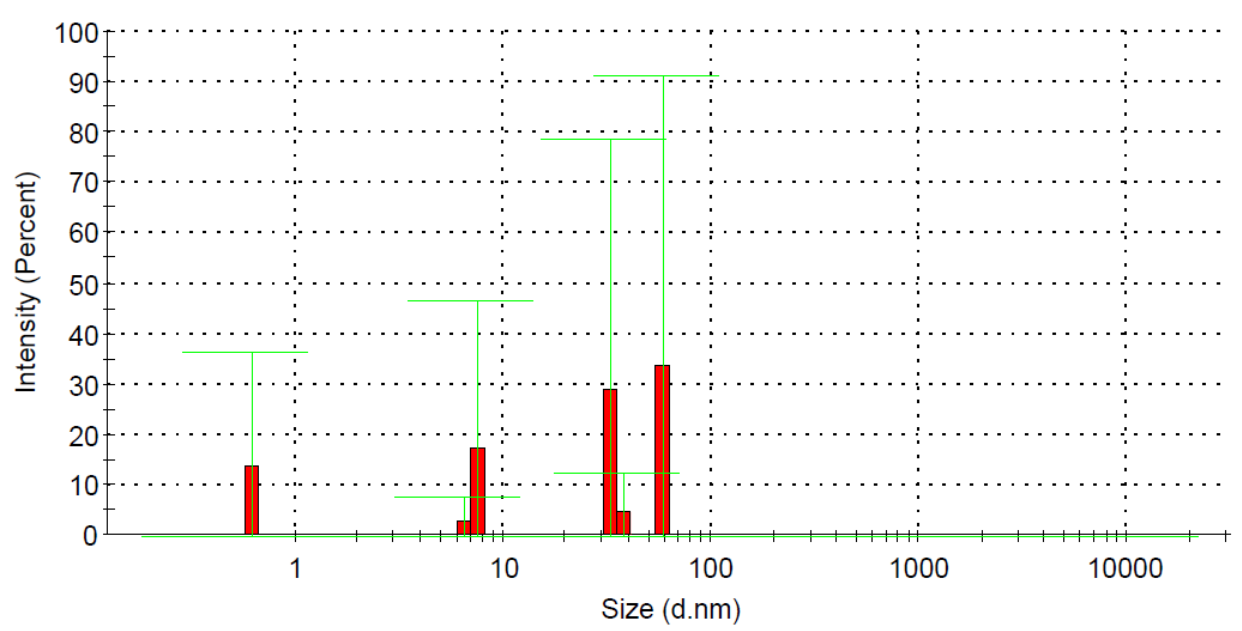

Figure 5 Distribution of SZG3 self-assembled nanoparticles after 15 min ultrasound

After 15 minutes of ultrasound, SZG3 was self-assembled into nanoparticles of different sizes at $37{ }^{\circ} \mathrm{C}$. It can be seen from Figure 5 that nanoparticles are mainly distributed between 30-60 nm. 
As shown in Figure 6, after 30 minutes of ultrasound, the size of $40.4 \%$ of SZG3 nanoparticles is $78.82 \mathrm{~nm}$, and that of
$59.6 \%$ is $91.28 \mathrm{~nm}$. This shows that the ultrasonic time affects the formation of different sizes of SZG3 nanoparticles.

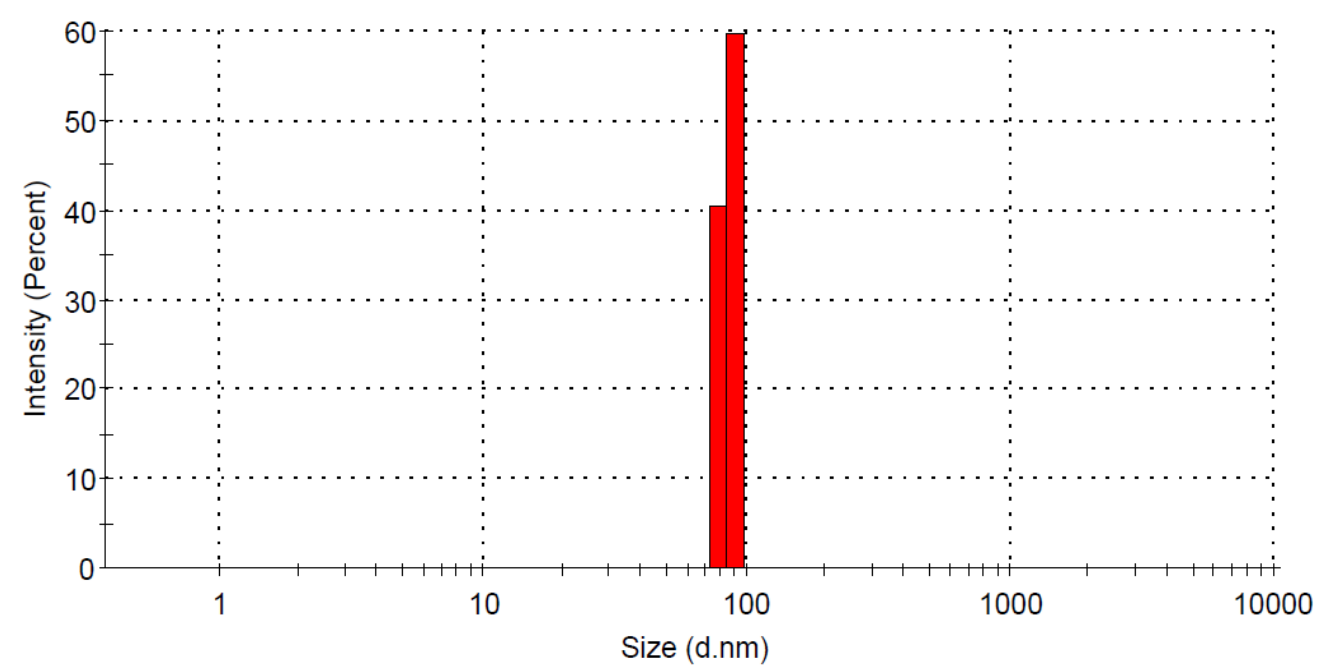

Figure 6 Distribution of SZG3 self-assembled nanoparticles after 30 min ultrasound

Compared with SZG3, SZG5 does not self assemble into nanoparticles, which may be due to its high liposolubility. This shows that the appropriate liposolubility is very important in the formation of nanoparticles.

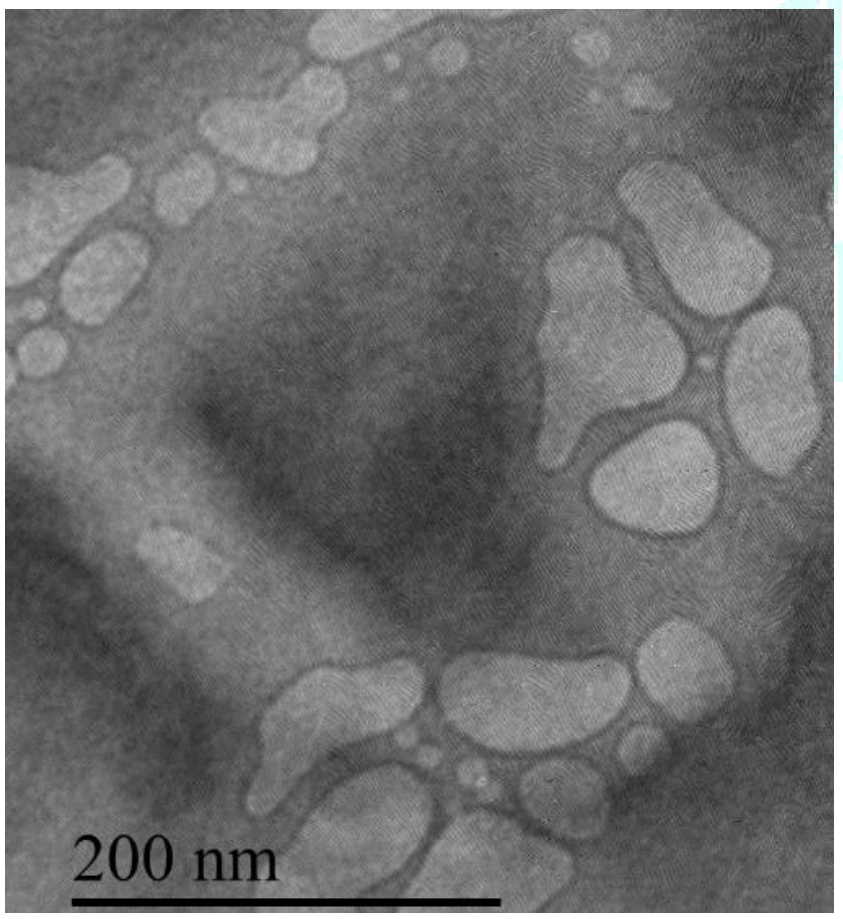

Figure 7 Imaging diagram of SZG3 self-assembled nanoparticles after 30 min ultrasound

As shown in Figure 7, SZG3 is self-assembled into nanoparticles of about $90 \mathrm{~nm}$, which has potential tumor targeting properties.

\section{CONCLUSION}

Cancer kills millions of people around the world every year, but so far there is no effective way to cure cancer. In recent years, researchers have made a lot of achievements in cancer chemotherapy, which improves the sensitivity of chemotherapy drugs to cells and reduces the side effects of drugs. However, the cure rate of surgery and radiotherapy and chemotherapy did not reach a high level. As cancer is a chronic disease, the number of gene mutations increases with the growth of people's age. However, after radiotherapy, chemotherapy and surgery, the human body can not completely eliminate all cancer cells, resulting in a high recurrence rate of cancer. Through the modification of antibacterial peptide, it has stronger cationic property and better targeting property; through the nano self-assembly experiment, SZG3 nanoparticles are obtained, which has stronger theoretical targeting property. Because of the enhanced permeability and retention (EPR) effect of nanoparticles, SZG3 nanoparticles can enter the blood vessels of tumor tissue better in theory by intravenous injection. This provides a strategy for the development of anticancer peptide nanoparticles with higher activity in the future.

\section{ACKNOWLEDGMENTS}

This work was supported by the Shandong Government sponsored study abroad program scholarship (NO. 201801016); the Project of Medical and Health Science Technology Development Program in Shandong Province of China (2016WS0242); and the Linyi Science and Technology Innovation and Development Project (Medicine) [201818033].

\section{CONFLICTS OF INTEREST}

The authors declare no conflict of interest, financial or otherwise. 


\section{REFERENCES}

1. Bray F, Ferlay J, Soerjomataram I, Siegel RL, Torre LA, Jemal A. Global cancer statistics 2018: GLOBOCAN estimates of incidence and mortality worldwide for 36 cancers in 185 countries. CA: a cancer journal for clinicians. 2018;68(6):394-424.

2. Housman G, Byler S, Heerboth S, Lapinska K, Longacre M, Snyder $\mathrm{N}$, et al. Drug resistance in cancer: an overview. Cancers. 2014;6(3):1769-92.

3. Yamaguchi Y, Ouchi Y. Antimicrobial peptide defensin: identification of novel isoforms and the characterization of their physiological roles and their significance in the pathogenesis of diseases. Proceedings of the Japan Academy, Series B. 2012;88(4):152-66.

4. Scocchi M, Tossi A, Gennaro R. Proline-rich antimicrobial peptides: converging to a non-lytic mechanism of action. Cellular and Molecular Life Sciences. 2011;68(13):2317-30.

5. Yedery RD, Jerse AE. Augmentation of Cationic Antimicrobial Peptide Production with Histone Deacetylase Inhibitors as a Novel Epigenetic Therapy for Bacterial Infections. Antibiotics.

2015;4(1):44-61.

6. Malvisi M, Stuknytè M, Magro G, Minozzi G, Giardini A, De Noni I, et al. Antibacterial activity and immunomodulatory effects on a bovine mammary epithelial cell line exerted by nisin A-producing Lactococcus lactis strains. Journal of dairy science.

2016;99(3):2288-96.
7. Hu E, Wang D, Chen J, Tao X. Novel cyclotides from Hedyotis diffusa induce apoptosis and inhibit proliferation and migration of prostate cancer cells. International journal of clinical and experimental medicine. 2015;8(3):4059-65.

8. Du Q, Hou X, Wang L, Zhang Y, Xi X, Wang H, et al. AaeAP1 and AaeAP2: Novel Antimicrobial Peptides from the Venom of the Scorpion, Androctonus aeneas: Structural Characterisation, Molecular Cloning of Biosynthetic Precursor-Encoding cDNAs and Engineering of Analogues with Enhanced Antimicrobial and Anticancer Activities. Toxins. 2015;7(2):219-37.

9. Sun Z-G, Li Z-N, Zhao L-H, Zhang J-M. Research Progress of Anti-breast Cancer Peptides. International Journal of Innovative Research in Medical Science. 2019;4(08):504-6.

10. Esmaeili MA, Abagheri-Mahabadi N, Hashempour H, Farhadpour M, Gruber CW, Ghassempour A. Viola plant cyclotide vigno 5 induces mitochondria-mediated apoptosis via cytochrome $\mathrm{C}$ release and caspases activation in cervical cancer cells. Fitoterapia.

2016;109:162-8.

11. Narayanan S. Sialic acid as a tumor marker. Annals of Clinical \& Laboratory Science. 1994;24(4):376-84.

12. Manzo G, Scorciapino MA, Wadhwani P, Bürck J, Montaldo NP, Pintus M, et al. Enhanced amphiphilic profile of a short $\beta$-stranded peptide improves its antimicrobial activity. PloS one. 2015;10(1):e0116379. 